\title{
Preparation and tribological properties of 3D network polymer-based nanocomposites reinforced by carbon nanofibers
}

\author{
Yixing Zhu, Huaiyuan Wang ${ }^{*}$, Lei Yan, Rui Wang, Yanji Zhu \\ College of Chemistry and Chemical Engineering, Northeast Petroleum University, 163318, Daqing, China
}

\begin{abstract}
A new robust three-dimensional (3D) network epoxy (EP) -based nanocomposite was fabricated via vacuum assisted resin transfer molding (VARTM) method. Carbon nanofibers (CNFs) and 3D polyimide (PI) fiber felt were utilized to improve the mechanical and tribological properties of the prepared EP nanocomposites. Results indicated that both the friction coefficients and wear rates of CNFs/PI/EP nanocomposites were lower than the other two comparative materials at various loads and velocities. CNFs/PI/EP nanocomposites obtained superior tribological properties, which enhanced the wear resistance by 18 times compared with pure EP under the applied load of 1.2 MPa. The worn surface and wear mechanism of composites were analyzed by a scanning electron microscope (SEM). Additionally, CNFs/PI/EP nanocomposites also exhibited remarkable improvements in the mechanical properties. These improved properties could be attributed to the synergistic effect between PI fiber felt and CNFs. The 3D PI fiber felt was used as structural skeleton reinforcing while the CNFs played its role in enhancing interface bonding strength between EP matrix and PI fiber felt. The CNFs could also act as solid lubrication and anti-friction agent in the composites.
\end{abstract}

Keywords: Polymer-matrix composite; Wear testing; Sliding wear; Surface topography

\footnotetext{
*Corresponding author: wanghyjiji@163.com Phone: (086) 459-6503083 


\section{Introduction}

In recent years, three-dimensional (3D) network polymer-based nanocomposites as promising materials have attracted intensive interest in scientific and practical applications [1]. Compared with traditional composites, new-type composites reinforced by 3D textile fabrics can enhance mechanical strength to solve interlaminar fracture problem effectively [2-3]. Up to now, various three-dimensional (3D) network nanocomposites have been fabricated by means of different techniques, such as chemical spray deposition [4], template method [5] and microfluidic infiltration [6]. It is believed that the application of these 3D network nanocomposites can broaden the investigation of the mechanics and tribology in the materials field.

Epoxy resin (EP) has been widely used in engineering and construction industries owing to its excellent properties, such as high adhesion, good mechanical properties, high chemical corrosion resistance and dimensional stability [7-9]. However, the major defects of poor fracture resistance and high wear rate of EP are still urgently need to improve for many tribological applications [10, 11]. Various kinds of EP composites reinforced by fillers have been developed for several decades. For instance, Allaoui et al. [12] found that adding 3 wt.\% multiwalled carbon nanotubes (MWCNTs) into epoxy composite decreased the wear rate by $77 \%$ compared to pure epoxy. The obtained better wear resistance of the MWCNTs/epoxy composite can be explained by the high mechanical property and dispersion quality of CNTs in epoxy matrix. Fan et al. [13] fabricated epoxy composites enhanced by strategically injecting MWCNT/epoxy suspensions into stationary glass fiber mats. This research contributes to an increase in the interlaminar shear strength (ILSS) by $33 \%$ of the prepared composites. Unfortunately, compared with organic polymer fibers, glass fiber with high brittleness is difficult to satisfy more rigorous demands in industrial application [14]. Organic 
polymer fibers with continuous macromolecular chain possess of excellent flexibility especially in high temperature, which can enhance the mechanical and tribological properties of the epoxy-based composites efficiently [15].

Polyimide (PI) fibers as special engineering materials have enormous potentials based on the high elasticity modulus, high thermal stability and wear resistance [16, 17]. PI fiber felt with distinct 3D elastic network structures can also be used as skeleton structure to reinforce EP composites. Moreover, in order to relieve the phenomena of the interfacial separation between fibers and EP composites, nanofibers or nanoparticles are usually added to fill the micro zone of composites owing to their unique properties such as small size effect, boundary effect and quantum effect $[18,19]$. Carbon nanofibers $(\mathrm{CNFs})$ as a common nanofillers are suitable to reinforce polymeric materials due to their excellent electric conductivity, thermostability and self-lubricating properties $[20,21]$. The characteristics of small-size and high strength of CNFs can strengthen the small region within the materials, realizing micro-area increasing and microscopic wear resistance [22]. On the other hand, the synergistic effect between CNFs and PI can enhance structural strength and interface bonding force of nanocomposites. Accordingly, the EP nanocomposites with interpenetrating 3D networks which possess of outstanding mechanical and tribological properties can be hopefully achieved.

In this work, we fabricated robust EP-based nanocomposites with 3D network structures by means of vacuum assisted resin transfer molding (VARTM) method. The interpenetrating 3D network structures were designed by incorporating 3D PI fiber felt and CNFs. The friction and wear tests of pure epoxy, PI/EP and CNFs/PI/EP composites were carried out at different loads and sliding velocities under dry sliding condition. The worn and counterpart surfaces of composites 
were studied by a scanning electron microscopy (SEM). In order to analyze the structure and wear mechanism of composites, a series of mechanical properties were comparatively investigated.

\section{Experimental}

\subsection{Materials}

In this work, Araldite LY1564SP epoxy resin with low viscosity and corresponding XB3487 curing agent were provided by Huntsman Advanced Materials (Nanjing) Co., Ltd, China. Three-dimensional polyimide fiber felt was purchased by Changchun HipolyKing Co., Ltd, China. The dimensions of the PI fiber felt are $100 \mathrm{~cm} \times 50 \mathrm{~cm} \times 4 \mathrm{~mm}$ and the felt can be cut to any desired size as needed. The diameter of single fiber is approximately $8 \mu \mathrm{m}$. The mechanical properties of this PI fibers are as follows: Tensile strength $>100 \mathrm{MPa}$; Impact strength $>28 \mathrm{~kJ} / \mathrm{m}^{2}$; Bending strength $>170 \mathrm{MPa}$; Breaking elongation(\%)>20. Vapor grown carbon nanofibers (CNFs, grade PR-24-XT-LHT) with an average diameter of $150 \mathrm{~nm}$ and a length of $50-200 \mathrm{~mm}$ were obtained from Pyrograf Products, Inc. Vacuum bags applied in VARTM process were purchased from Beijing Inova Technology Co., Ltd, China.

\subsection{Pre-treatment}

Pristine CNFs were treated by immersing the CNFs in concentrated nitric acid (4 mol/L) via magnetic stirring at $60^{\circ} \mathrm{C}$ for $3 \mathrm{~h}$. After the acid treatment, the CNFs was filtered and washed with deionized water until the $\mathrm{pH}$ value was approximately 7 . Then, the CNFs were dried in a vacuum drying oven at $100{ }^{\circ} \mathrm{C}$ overnight. Three-dimensional polyimide fiber felt was cut to the certain size according to the demand for different test and dried in a vacuum drying oven at $80{ }^{\circ} \mathrm{C}$ for $2 \mathrm{~h}$.

\subsection{Preparation of CNFs/PI/EP nanocomposites}

Fig. 1 shows the fabricating process of CNFs/PI/EP nanocomposites. The prepared CNFs were 
incorporated to the epoxy resin at proper mass fractions $(0.5,1.0$, and 1.5 wt.\%) via magnetic stirring at $40{ }^{\circ} \mathrm{C}$ for $1 \mathrm{~h}$. The curing agent was added into the above prepared resin solution with an epoxy resin/curing agent weight ratio 100/34. Ultrasonic vibration was conducted at room temperature for 10 min to compound resin and curing agent sufficiently. Then the epoxy-based nanocomposites reinforced by polyimide fiber felt and CNFs were fabricated by the vacuum assisted resin transfer molding (VARTM) process [23] by transferring the prepared epoxy resin into polyimide fiber felt. The volume fraction of PI in the composite was about $23 \%-24 \%$. The whole process was conducted in vacuum conditions to remove bubbles in the composites. The unformed composites were cured by a plate vulcanizing machine, which were heated and pressurized at $80{ }^{\circ} \mathrm{C}$ over $1.5 \mathrm{~h}$ and followed by $5 \mathrm{~h}$ at $100{ }^{\circ} \mathrm{C}$ under an applied load of $1 \mathrm{MPa}$. For comparison, the pure $\mathrm{EP}$ and $\mathrm{PI} / \mathrm{EP}$ composites were also prepared at the same curing procedure.

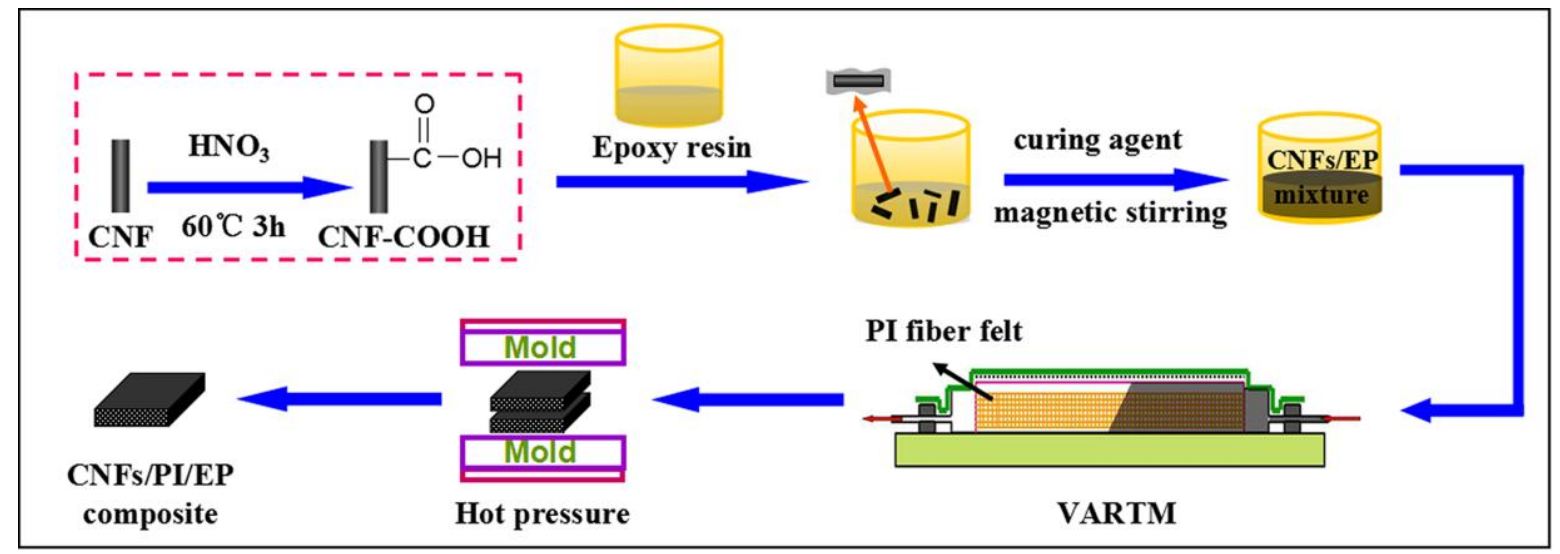

Fig.1. Flowchart for the preparation of CNFs/PI/EP nanocomposites.

\subsection{Characterization}

\subsubsection{Morphology of CNFs/PI/EP nanocomposites}

The morphologies of PI fiber felt, fracture surfaces of PI/EP and CNFs/PI/EP composites were comparatively investigated by a $\Sigma$ IGMA scanning electron microscope (SEM, ZEISS, Germany). Fracture surfaces of PI/EP and CNFs/PI/EP composites were prepared as following procedures: 
Composites was handled with liquid nitrogen frozen and conducted the process of brittle fracture. Fix a prepared sample and then exert a certain force to break the sample.

\subsubsection{Mechanical properties}

Tensile and bending properties of the composites were measured using a universal testing machine (HDW-20KN, Huayang Experimental Equipment, China). Tensile test was conducted according to the American Society for Testing and Materials (ASTM, 2010, standard D638-10). The specimens were prepared following the standard ASTM D638 requirement. Five samples were tested at the speed of $2 \mathrm{~mm} / \mathrm{min}$ and the average value from five measurements was used. Bending test was carried out following the standard ASTM D790-10. Testing speed was $2 \mathrm{~mm} / \mathrm{min}$ ruled according to the standard ASTM. At least five specimens were tested and the average value was presented. Shore D durometer (LD-J, Wenzhou Haibao Instruments, China) was used to investigate the hardness of composites.

\subsubsection{Friction and wear test}

In this section, the friction and wear tests of pure EP, PI/EP and CNFs/PI/EP composites were conducted by using a pin-on-disc friction and wear tester (MPX-2000, Xuanhua Testing factory, China). The schematic diagram of friction and wear tests is shown in Fig. 2. The specimen should be machined to a dimension of $5 \mathrm{~mm} \times 4 \mathrm{~mm} \times 4 \mathrm{~mm}$. AISI 1045 steel as a kind of commonly used bearing steel possesses of excellent mechanical properties, wear/ heat resistance and exceptional processability, which is regarded as an appropriate counterpart material in the friction test. Thus a AISI 1045 steel ring (outside diameter of $37 \mathrm{~mm}$ and inner diameter of $22 \mathrm{~mm}$ ) was selected as the counterpart surface. The specimens and counterpart rings were machined and polished with 1000 grade sandpaper to an initial surface roughness of $0.15-0.3 \mu \mathrm{m}$ before tribological tests. Before the 
formal tribological tests, we conducted some preliminary experiments and investigated relevant information to estimate the load-carrying capacity and wear resistance of EP and PI composites. Then, synthesizes the friction velocity and load which epoxy and polyimide composites can afford, the tribological conditions were determined. All the friction and wear tests were carried out under dry sliding with the sliding velocities of $0.51 \mathrm{~m} / \mathrm{s}$ and $0.76 \mathrm{~m} / \mathrm{s}$. The applied loads were $0.4 \mathrm{MPa}$, 0.8 MPa, 1.2 MPa, 1.6 MPa, 2.5 MPa, 5.0 MPa and the testing duration was $60 \mathrm{~min}$.

In this work, three tribological parallel experiments of each specimen were performed and the mean value of three testing results was adopted. During the test, the frictional torque was measured by strain-gauge sensor on the friction machine and recorded by computer continuously. The friction coefficient was calculated by the expression:

$$
\mu=\frac{M}{r \times F_{N}}
$$

where $M$ is the frictional torque $(\mathrm{N} \mathrm{m}), r$ is the rotary radius of specimen $(\mathrm{m}), F_{N}$ is the vertical load $(\mathrm{N})$.

The wear rate, an important parameter to describe the wearing performance, was calculated by the equation:

$$
W r=\frac{\Delta m}{\rho \times F_{N} \times L}
$$

Where $\Delta m$ is the mass loss $(\mathrm{g}), \rho$ is the density of the specimen $\left(\mathrm{g} / \mathrm{cm}^{3}\right), F_{N}$ is the vertical load $(\mathrm{N})$, and $L$ is the sliding distance of the specimen $(\mathrm{m})$.

The counterpart temperatures of composites in the friction zone were measured by infrared digital thermometer. The morphologies of worn and counterpart surfaces were investigated by means of a scanning electron microscope (ZEISS, Germany). 


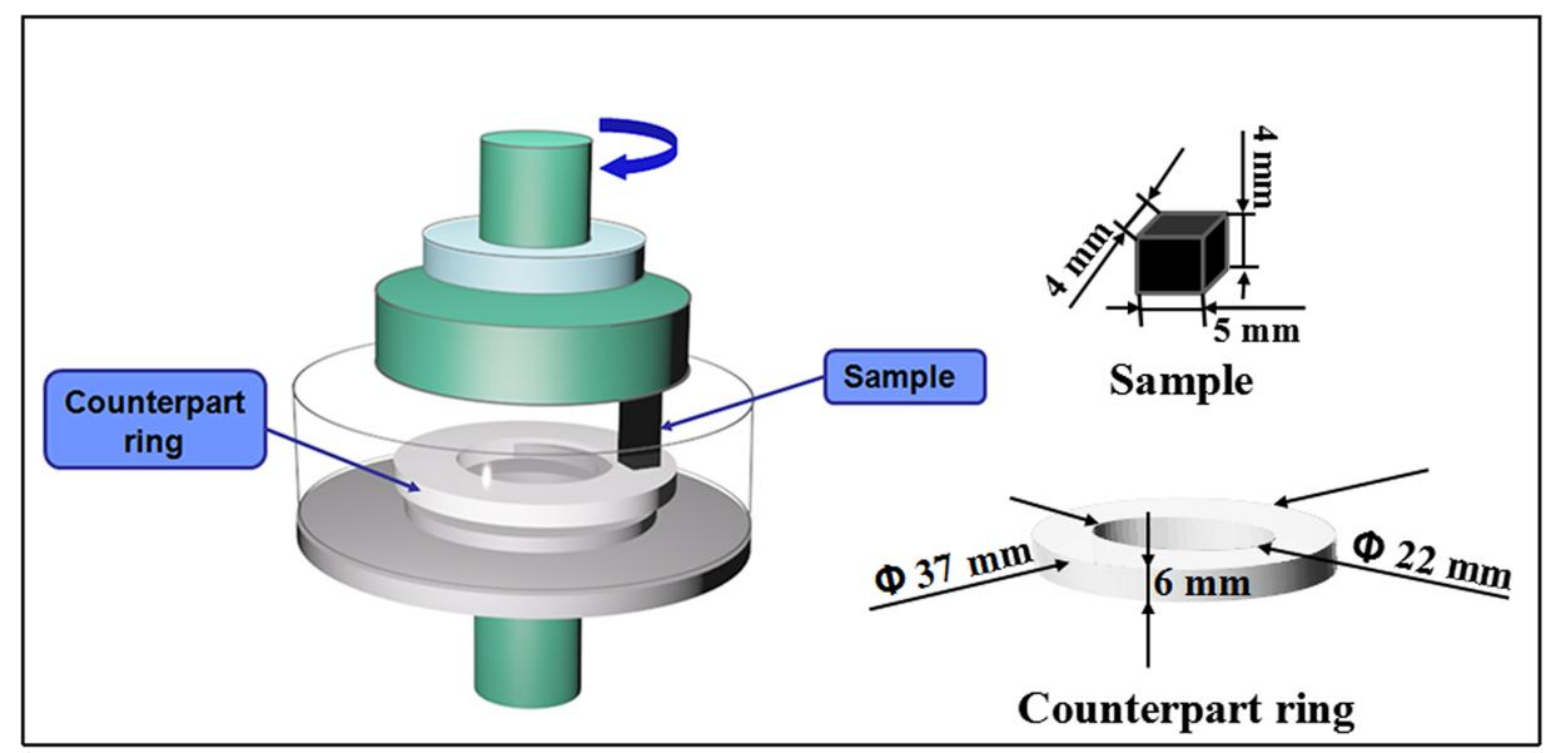

Fig.2. Experiments diagram of friction and wear tests.

\section{Results and discussion}

\subsection{Morphology of CNFs/PI/EP nanocomposites}

Fig. 3 shows the optical and SEM images of PI fiber felt, PI/EP and CNFs/PI/EP composites. It can be seen that the thickness of the PI fiber felt is approximately $4 \mathrm{~mm}$ (Fig. 3a). From the SEM image of the PI fiber felt in Fig. 3b, we can observe the 3D spatial network structure fabricated by the homogeneous PI fibers. The internal 3D spatial network structure can overcome the brittleness defect of epoxy and consume most of the pressure on the composites, enhancing the mechanical strength of the prepared nanocomposites significantly. Using the PI fiber felt as skeleton, PI/EP and CNFs/PI/EP composites with cross-linked 3D network skeleton can be obtained by injecting the as-treated epoxy resin and hot-pressing methods (Fig. 3c, 3e). As shown in Fig. 3e, the sample changed from orange to black attributing to the introduction of CNFs. Fig. $3 \mathrm{~d}$ and Fig. $3 \mathrm{f}$ depicts the SEM images of cross section of PI/EP and CNFs/PI/EP composites. In Fig. 3f, the interface junction between PI fibers and epoxy matrix is emphatically marked by yellow ovals. There is no gaps and pores in the interfaces between two phases, and PI fibers inlaid into the epoxy matrix 
steadily, showing a robust interpenetrating structure in a three-dimensional pattern. It can be indicated that the interface bonding strength in the composites has been improved greatly. Moreover, in Fig. 3f, only PI fibers can be distinctly observed in fracture surface of the prepared nanocomposites because of the enormous diameter difference between CNFs $(150 \mathrm{~nm})$ and PI fibers $(8 \mu \mathrm{m})$. No obvious aggregation of CNFs is detected in the cross section, which indicates a uniform dispersion of the modified CNFs throughout the composites. The homogeneous distribution of the CNFs driven by the compatibility between PI fillers and epoxy matrix can help to solve the defects of interlaminar fracture, which may protect the epoxy matrix from being damaged in the harsh conditions.

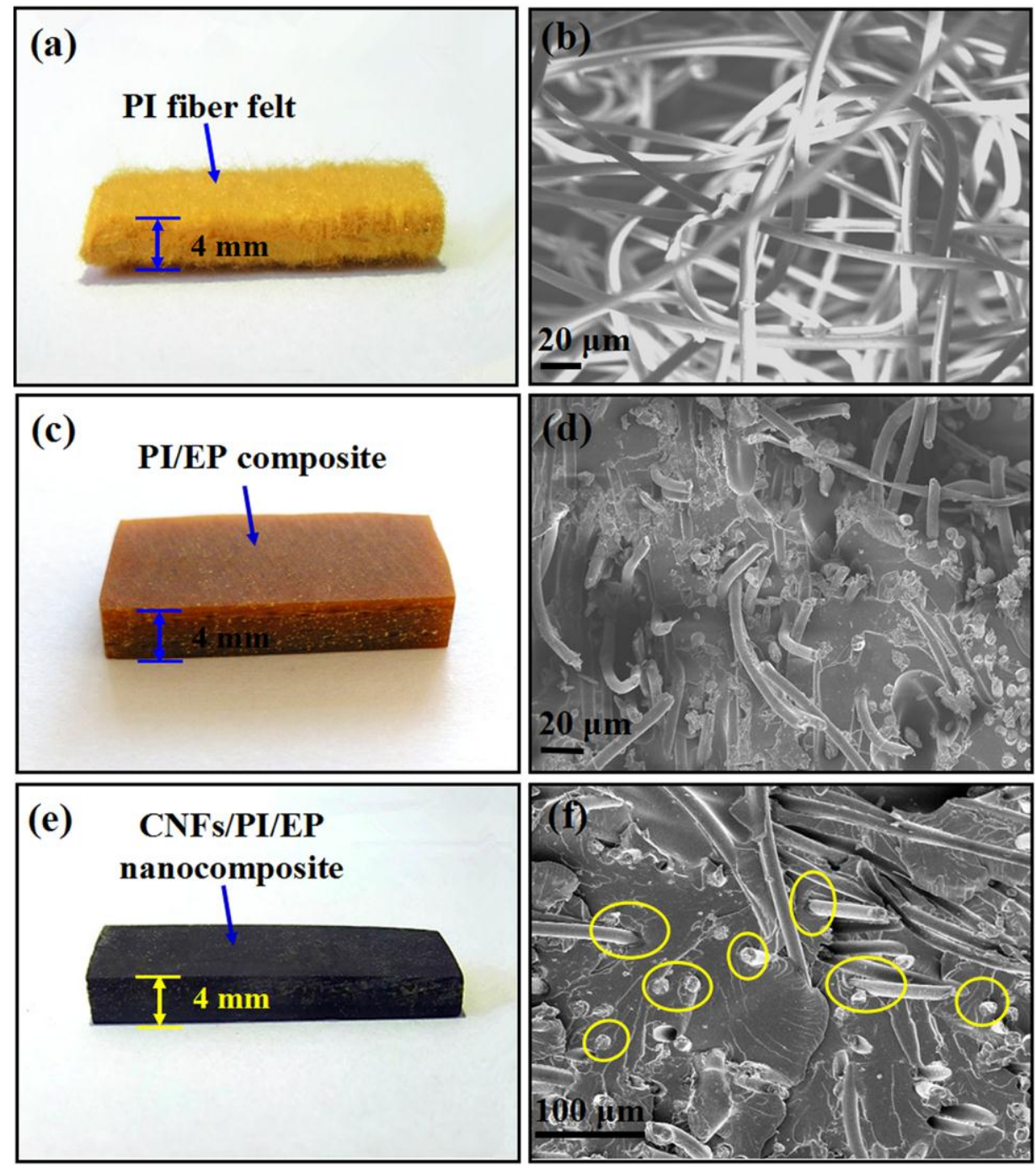


Fig.3. Optical micrographs of PI fiber felt (a), PI/EP composites (c) and CNFs/PI/EP nanocomposites (e). SEM images of PI fiber felt (b) and cross section of PI/EP composites (d) and 1.0 wt.\% CNFs/PI/EP nanocomposites (f).

\subsection{Mechanical properties}

Mechanical properties of pure EP, PI/EP and $1.0 \mathrm{wt} . \% \mathrm{CNFs} / \mathrm{PI} / \mathrm{EP}$ composites are shown in Table 1. For pure EP, its average tensile strength, bending strength and shore hardness is $72 \mathrm{MPa}$, $90 \mathrm{MPa}$ and $75 \mathrm{HD}$, respectively. Compared to pure EP, the 3D composites only reinforced by PI fiber felt demonstrates an improvement of the tensile strength (52.8\%), bending strength (94.4\%) and shore hardness $(13.3 \%)$. The improvements in mechanical properties of PI/EP composites can be attributed to the following reasons. On the one hand, the 3D skeleton structure composed of interpenetrating PI fibers can resist stress to protect the epoxy matrix. On the other hand, the relatively good interaction between PI fiber felt and epoxy matrix avoids cracks and damages of the composites under heavy loads. Nevertheless, it may still have many micro interstices in the composites. In this study, compared to pure EP, the introduction of $1.0 \mathrm{wt} . \%$ CNFs can obviously enhance the tensile strength $(68.1 \%)$, bending strength $(107.8 \%)$ and shore hardness $(18.7 \%)$ of $\mathrm{CNFs} / \mathrm{PI} / \mathrm{EP}$ nanocomposites. As a result, the modified $1.0 \mathrm{wt} . \% \mathrm{CNFs}$ play an improvement role in the interfacial strength and interfacial adhesion between PI fibers and EP matrix [24]. CNFs are filled in the interstices between the reinforcing PI fibers and matrix to occupy the micro regions. Then the local stress can be efficiently transferred into the tougher fibers, thus prevent the network skeleton of felt peeling from the nanocomposites. Hence, the CNFs/PI/EP nanocomposites present the higher mechanical performance. 
Table 1 Mechanical properties of pure EP, PI/EP and 1.0 wt.\% CNFs/PI/EP composites

\begin{tabular}{cccc}
\hline Materials & $\begin{array}{c}\text { Tensile strength } \\
(\mathrm{MPa})\end{array}$ & $\begin{array}{c}\text { Bending strength } \\
(\mathrm{MPa})\end{array}$ & $\begin{array}{c}\text { Shore hardness } \\
(\mathrm{HD})\end{array}$ \\
\hline Pure EP & $72 \pm 2$ & $90 \pm 2$ & $75 \pm 1$ \\
PI/EP & $110 \pm 1$ & $175 \pm 2$ & $85 \pm 1$ \\
$\mathrm{CNFs} / \mathrm{PI} / \mathrm{EP}$ & $121 \pm 1$ & $187 \pm 2$ & $89 \pm 1$ \\
\hline
\end{tabular}

\subsection{Friction and wear behaviors}

\subsubsection{Effect of CNFs content}

The tribological properties of CNFs/PI/EP nanocomposites with $0.5 \mathrm{wt} . \%$ to $1.5 \mathrm{wt} . \%$ of CNFs under the conditions of $0.76 \mathrm{~m} / \mathrm{s}$ and $1.2 \mathrm{MPa}$ are comparatively shown in Table 2. Apparently, the friction coefficients of CNFs/PI/EP nanocomposites exhibit almost no change with increasing weight ratio of CNFs. While the test results demonstrate that the wear rates of CNFs/PI/EP nanocomposites reach the lowest value with the addition of $1.0 \mathrm{wt} \%$ CNFs. This superior wear resistance may be attributed to the homogeneous distribution of CNFs and favourable adhesive strength in the matrix. Whereas further addition of CNFs increases the wear rate of CNFs/PI/EP nanocomposites, which may because of the fact that excess CNFs lead to the agglomeration of nanoparticles and unevenness of the composite structures. Through the combination of the best anti-wear performance achieved at the addition of $1.0 \mathrm{wt} \% \mathrm{CNFs}$, we can confirm the optimal addition of CNFs. Therefore, a detailed investigation of the friction and wear properties of $1.0 \mathrm{wt} . \%$ CNFs/PI/EP nanocomposites under different conditions was analyzed comprehensively. 
Table 2 Tribological properties of CNFs/PI/EP nanocomposites with different CNFs contents, 1.2 $\mathrm{MPa}, 0.76 \mathrm{~m} / \mathrm{s}$

\begin{tabular}{ccc}
\hline Materials & Friction coefficient & $\begin{array}{c}\text { Wear rate } \\
\left(10^{-14} \mathrm{~m}^{3} / \mathrm{Nm}\right)\end{array}$ \\
\hline Pure EP & $0.62 \pm 0.010$ & $102.5 \pm 3.2$ \\
PI/EP & $0.59 \pm 0.004$ & $11.0 \pm 1.5$ \\
0.5 wt.\% CNFs/PI/EP & $0.58 \pm 0.004$ & $7.1 \pm 2.3$ \\
1.0 wt.\% CNFs/PI/EP & $0.56 \pm 0.005$ & $5.6 \pm 1.0$ \\
1.5 wt.\% CNFs/PI/EP & $0.56 \pm 0.006$ & $9.6 \pm 2.5$ \\
\hline
\end{tabular}

\subsubsection{Effect of the applied load}

Fig. 4 dispicts the variation of wear rates and friction coefficients of pure EP, PI/EP and CNFs/PI/EP composites as a function of the applied load with a velocity of $0.76 \mathrm{~m} / \mathrm{s}$. The wear rates of pure EP continuously increases with the increasing applied load (Fig. 4a). When the applied load increases to 1.2 MPa, the wear rate of pure EP reaches up to $102.5 \times 10^{-14} \mathrm{~m}^{3} / \mathrm{Nm}$. However, when the applied load exceeds 1.2 MPa, pure EP begins to crumble and the friction tests could not proceed. This phenomenon may be explained by the accumulation of frictional heat and the poor carrying-capacity of pure EP [25]. It is noteworthy that the counterpart temperature of pure EP is very high during the course of friction. Continuously high temperature of counterpart surface accelerates plasticization of the epoxy matrix. Obvious plastic deformation of pure EP can be observed during the dry sliding. It can be inferred that the wear mechanism of pure EP may transfer from abrasive wear to ploughing wear and plastic deformation with the increasing load. Hence, the wear resistance of pure EP is sharply diminished.

Compared to pure EP, PI/EP and CNFs/PI/EP 3D composites exhibit lower wear rates under all range of the load. The main contributing factor for the improvement of wear resistance of the prepared 3D composites is the structural enhancement provided by introducing PI fiber felt, which 
can enhance the carrying-capacity of composites and maintain favorable morphologies effectively. When the applied load is $1.2 \mathrm{MPa}$, the wear rates of CNFs/PI/EP and PI/EP composites reach the minimum value. It is worth pointing out that the wear rate of CNFs/PI/EP nanocomposites $\left(5.6 \times 10^{-14} \mathrm{~m}^{3} / \mathrm{Nm}\right)$ is 18 -fold and 2-fold lower compared with pure EP $\left(102.5 \times 10^{-14} \mathrm{~m}^{3} / \mathrm{Nm}\right)$ and PI/EP composites $\left(11.0 \times 10^{-14} \mathrm{~m}^{3} / \mathrm{Nm}\right)$, respectively. The obtained superior anti-wear performance of CNFs/PI/EP nanocomposites is mainly ascribed to the synergistic effect between CNFs and PI fiber felt. The modified CNFs can fill up barren fiber region in the composites and enhance the adhesion between EP matrix and PI fiber felt, which further improve the structural strength of CNFs/PI/EP nanocomposites. In addition, CNFs act as solid lubricant reduce the frictional drag during the tribological tests, resulting in a lower wear rate of the composites [26].

As shown in Fig. 4b, the friction coefficients of the three composites present downward trends with the increase of applied load. Friction coefficient is influenced by micro deformation and contact-saturation. The micro deformation of friction contact surfaces becomes relatively obvious and the contact area gradually increases with the increasing load, leading to the decrease of the friction coefficients $[27,28]$. Moreover, the pure EP exhibits the highest friction coefficient and the CNFs/PI/EP nanocomposites obtain the lowest value among the three composites under all sliding conditions. The highest friction coefficient of pure EP is mainly due to the rather poor thermal conductivity and adhesive wear [29]. However, the prepared composites with 3D network structure improve the structural strength to reduce the shear stress, plus the lubricating effect of CNF leading to the decrease of friction coefficients. Additionally, the introduction of CNFs can form a network of thermal conductivity, enhancing the thermal conductivity to transmit the friction heat of the EP-based composites to the surroundings [30]. It can be confirmed by the results reported in Fig. 5, 
in which the counterpart temperature of CNFs/PI/EP composites is obviously lower than those of PI/EP composites and pure EP. The CNFs/PI/EP nanocomposites obtain both excellent heat resistance and thermal conductivity, which prevents the plasticizing of composites in the course of friction. All this can explain why the superior tribological performance of $\mathrm{CNFs} / \mathrm{PI} / \mathrm{EP}$ nanocomposites is achieved.
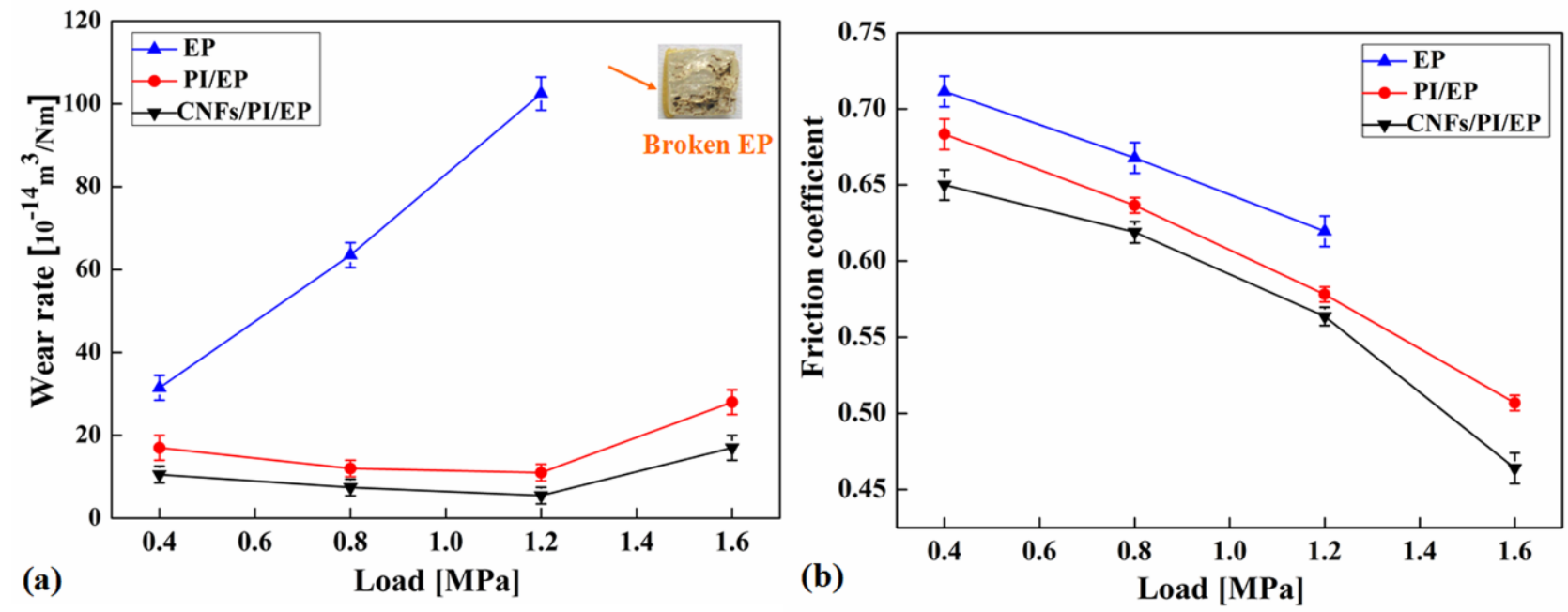

Fig.4. The wear rate (a) and friction coefficient (b) of pure EP, PI/EP composites and 1.0 wt.\% CNFs/PI/EP nanocomposites under different applied loads, $0.76 \mathrm{~m} / \mathrm{s}$.

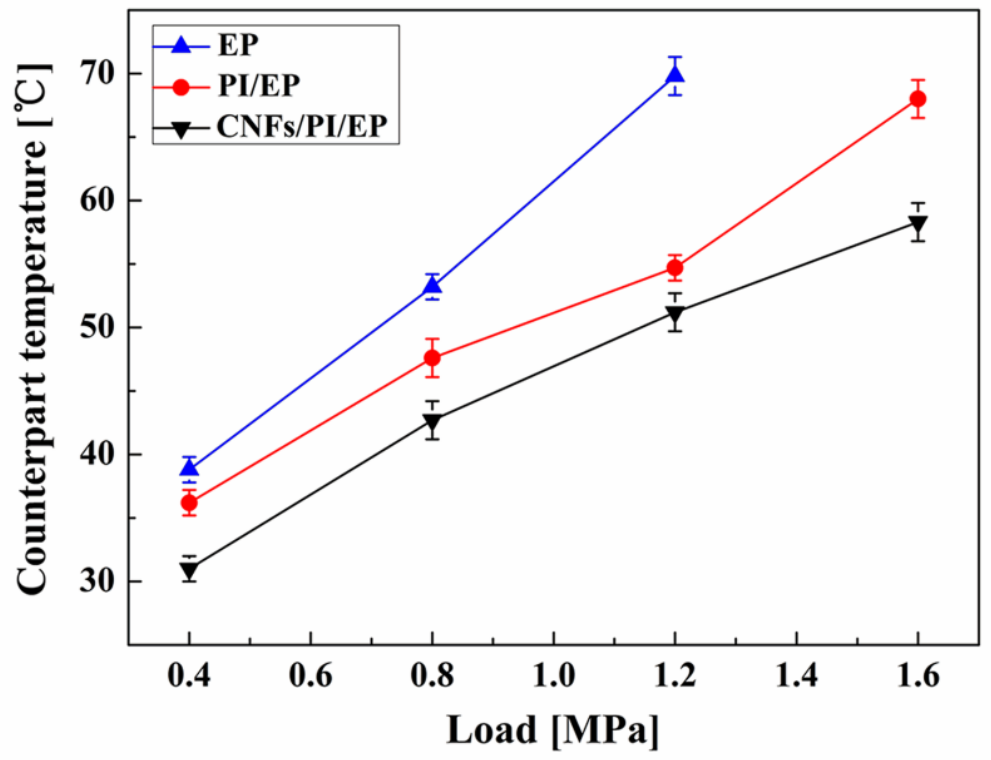

Fig.5. Counterpart temperatures of pure EP, PI/EP and 1.0 wt.\% CNFs/PI/EP composites under 
different applied loads and sliding velocity of $0.76 \mathrm{~m} / \mathrm{s}$ for $60 \mathrm{~min}$.

\subsubsection{Effect of velocity}

The effect of velocity with a constant load of $1.2 \mathrm{MPa}$ on the wear rate and the friction coefficient of composites is shown in Fig. 6. The wear rates of three composites all increase with the increasing velocity from $0.51 \mathrm{~m} / \mathrm{s}$ to $0.76 \mathrm{~m} / \mathrm{s}$, whereas CNFs/PI/EP nanocomposites have the lowest wear rates at various velocities (Fig. 6a). More heat generation and accumulation with the increasing of velocity result in a more serious impact to the structure and surface morphology of the composites. This explains why composites obtain higher wear rate at a higher velocity. Results indicated that when the velocity vary from $0.51 \mathrm{~m} / \mathrm{s}$ to $0.76 \mathrm{~m} / \mathrm{s}$, the wear rate of pure EP increases 3-fold, which of PI/EP and CNFs/PI/EP composites increase $75 \%$ and $31 \%$, respectively. On the one hand, PI fiber felt provide robust 3D interpenetrating polymer networks to hold back the deformation of composites. On the other hand, CNFs as reinforcing agent increase the contact area between fibers and polymer chains, showing strong interfacial interaction of CNFs/PI/EP nanocomposites. In Fig. 6b, the friction coefficients of these composites decrease slightly with the increasing velocity. The addition of CNFs can form thermal conductive network to dissipate friction heat, which contributes to the lowest friction coefficient. Hence, CNFs/PI/EP nanocomposites express remarkable wear resistance at different velocities. 

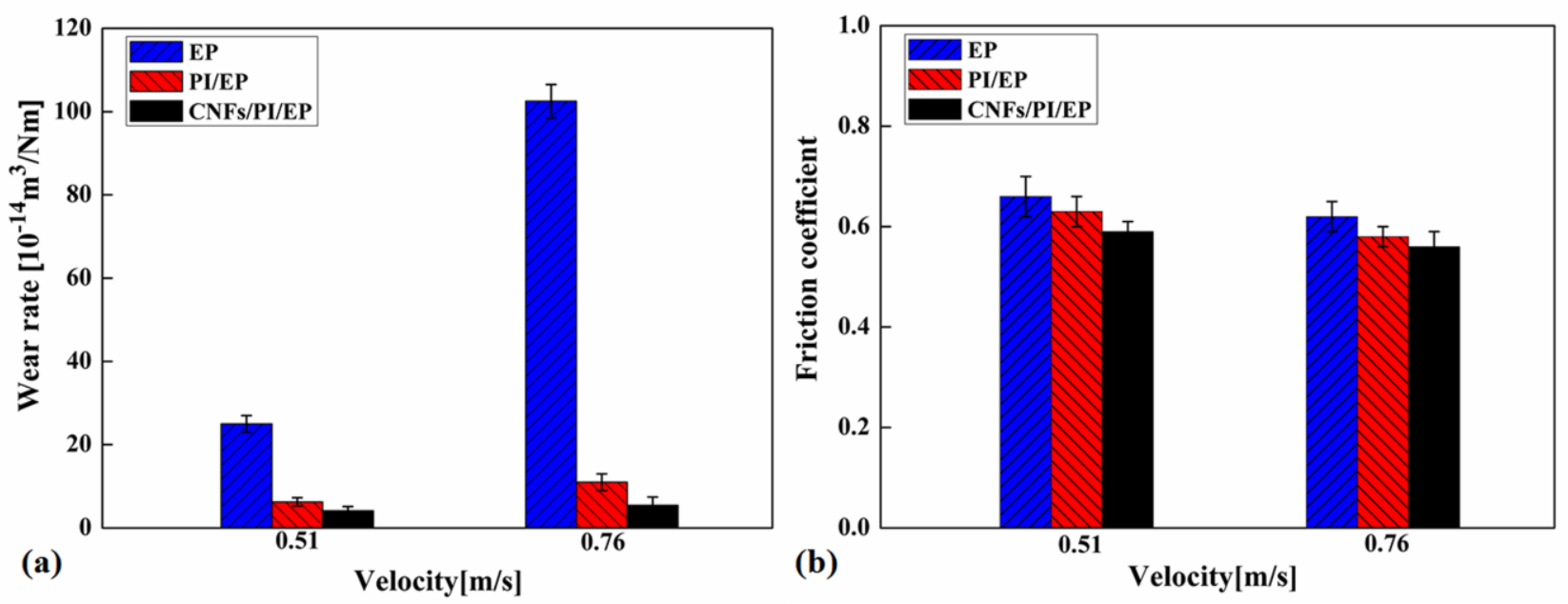

Fig.6. The wear rate (a) and friction coefficient (b) of pure EP, PI/EP composites and 1.0 wt.\% CNFs/PI/EP nanocomposites at velocities of $0.51 \mathrm{~m} / \mathrm{s}$ and $0.76 \mathrm{~m} / \mathrm{s}, 1.2 \mathrm{MPa}$.

\subsubsection{Tribological properties under rigorous condition}

The wear rates and friction coefficients of PI/EP and CNFs/PI/EP composites under the applied loads of 2.5 $\mathrm{MPa}$ and 5.0 $\mathrm{MPa}$ are shown in Fig. 7. Results show that both the wear rates and friction coefficients of CNFs/PI/EP nanocomposite are lower than that of PI/EP composites under rigorous condition, while pure EP can't endure these rigorous sliding conditions. In particular, the dominant mechanisms for composites are shifted to severe adhesive wear and delamination is more likely to occur in serious abrasion. While CNFs effectively enhance interface bonding strength of composites and prevent composites from exfoliating between fibers and epoxy matrix, displaying more superior tribological behaviors in particularly demanding applications. 

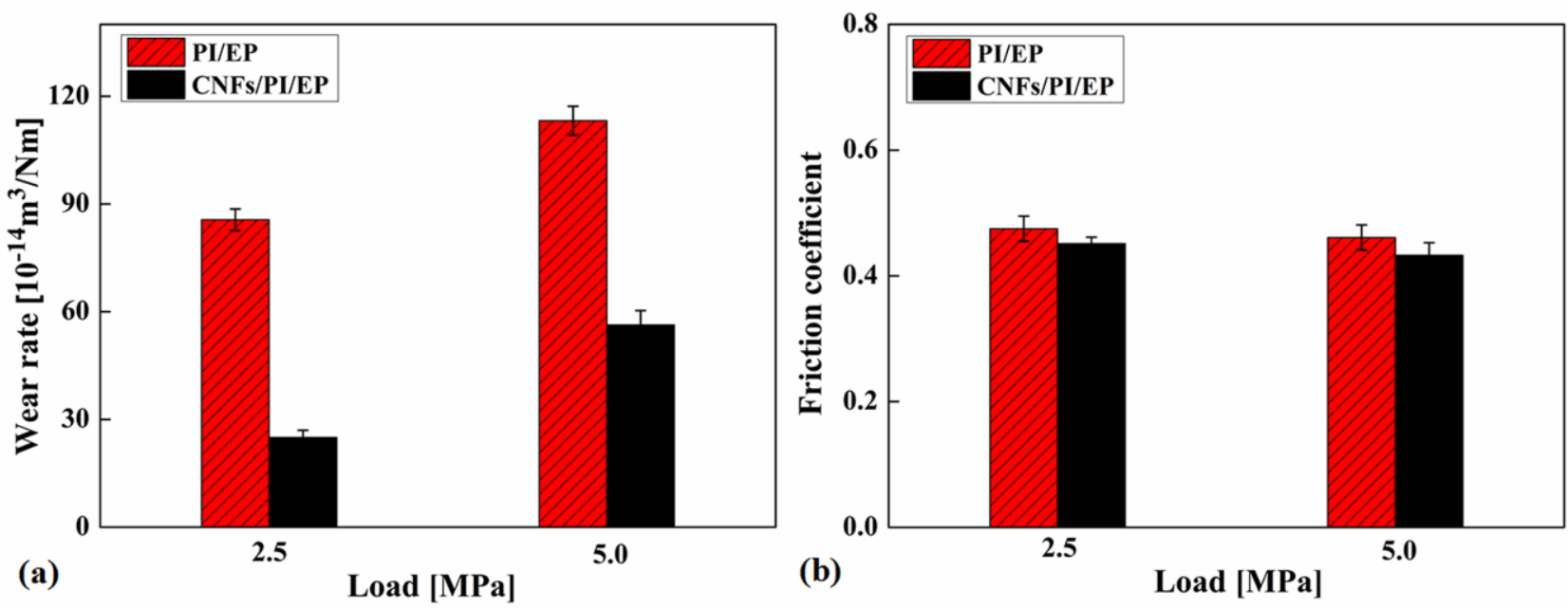

Fig.7. The wear rate (a) and the friction coefficient (b) of PI/EP and $1.0 \mathrm{wt.} \% \mathrm{CNFs} / \mathrm{PI} / \mathrm{EP}$ composites under the applied loads of $2.5 \mathrm{MPa}$ and $5.0 \mathrm{MPa}, 0.76 \mathrm{~m} / \mathrm{s}$.

\subsubsection{Microstructure of worn surfaces}

Fig. 8 shows the SEM micrographs of the worn surfaces of pure EP, PI/EP and CNFs/PI/EP composites under the sliding condition of $1.2 \mathrm{MPa}$ and $0.76 \mathrm{~m} / \mathrm{s}$. As shown in Fig. 8a, it is apparent that the worn surface of pure EP is characterized by many debris, visible adhesive marks and plastic deformation. The serious abrasive wear of pure EP causes the generation of ploughed furrows during the friction. The phenomenon is connected with the low wear resistance and the poor structural carrying capacity of the pure EP in sliding against the steel counterface. This fact indicates that severe ploughing wear and adhesive wear are the dominant wear mechanisms for pure EP. From Fig. 8b, we can observe the worn surface of PI/EP composites is relatively smooth, owing to the improvement in the carrying-capacity of composites. However, there is still a slight stripping between PI fiber felt and EP matrix during the dry sliding process, forming small furrows of naked PI fibers and debris. Hence, the main wear mechanisms of PI/EP composite are minor ploughing and adhesive wear.

The introduction of CNFs results in a quite smooth worn surface in spite of the existence of the 
PI fibers traces of CNFs/PI/EP nanocomposites (Fig. 8c), which means CNFs in the composites can sharply reduce the serious ploughing wear. The improved dispersion of the modified CNFs can effectively enhance the interfacial bonding of the nanocomposites, which can efficiently transmit the load from epoxy resin to fibers and relieve the phenomenon of fiber's exfoliation. The primary mechanism of CNFs/PI/EP nanocomposites is slight adhesive wear. Accordingly, the prepared CNFs/PI/EP nanocomposites can achieve the best wear resistance.
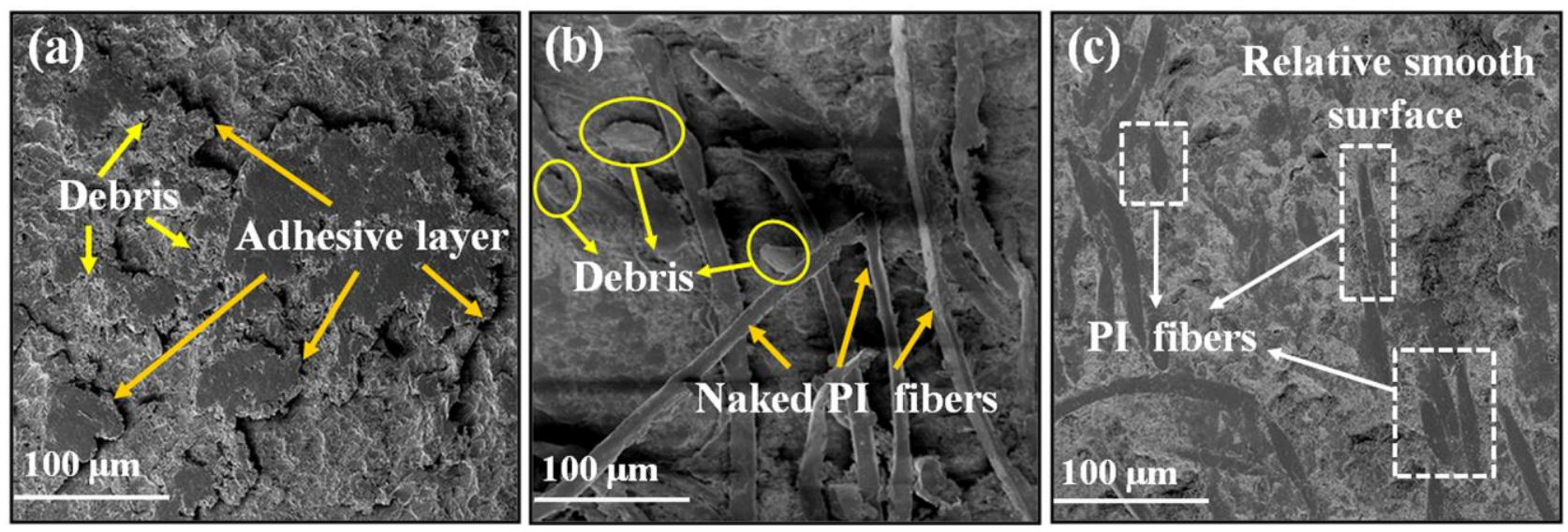

Fig.8. SEM morphology of the worn surfaces of (a) pure EP, (b) PI/EP composites, (c) 1.0 wt.\% CNFs/PI/EP nanocomposites under $1.2 \mathrm{MPa}$ and $0.76 \mathrm{~m} / \mathrm{s}$ conditions.

\subsubsection{Wear mechanisms of composites}

During the tribological test of different samples, the wear volumes of counterpart ring were measured and shown in Table 3. For pure EP, the wear volume of counterpart ring reaches the maximum value of $0.0019 \mathrm{~g}$ after friction for $60 \mathrm{~min}$. At the early stages of friction testing, the contact between EP and counterpart ring is interfacial contact. Nevertheless, pure EP specimen is easy to deform and crumble during the friction. When pure EP begins to crumble, block-like debris and fine debris fall on the counterpart surface, transforming the interfacial contact to the point-surface contact. So the wear volume of the counterpart steel increases. The result is consistent with the SEM morphology of the counterpart surfaces (Fig. 9a), which the surface represents 
serious wear damage. As for PI/EP and CNFs/PI/EP composites, the network structure of PI fiber felt supports the matrix EP and the composites maintain uniform surface morphology. So the contact modes between composites and counterpart steel are interfacial contact in the circumstances. On the other hand, fibers in the composites can be crushed into smaller debris. As the tribological test goes on, the debris can form a smooth film act as solid lubricants and recover the worn surface. Hence, the counterpart ring of PI/EP and CNFs/PI/EP composites suffered small loss.

Table 3 Wear volumes of the counterpart ring during the friction test of pure EP, PI/EP and 1.0 wt.\% CNFs/PI/EP composites, $1.2 \mathrm{MPa}, 0.76 \mathrm{~m} / \mathrm{s}$

\begin{tabular}{cc}
\hline Materials & $\begin{array}{c}\text { Wear volume } \\
(\mathrm{g})\end{array}$ \\
\hline Pure EP & $0.0019 \pm 0.0002$ \\
$\mathrm{PI} / \mathrm{EP}$ & $0.0012 \pm 0.0001$ \\
$\mathrm{CNFs} / \mathrm{PI} / \mathrm{EP}$ & $0.0008 \pm 0.0001$ \\
\hline
\end{tabular}

Fig. 9 demonstrates the SEM micrographs of the counterpart surfaces of pure EP, PI/EP, $\mathrm{CNFs} / \mathrm{PI} / \mathrm{EP}$ composites under the conditions of $1.2 \mathrm{MPa}$ and $0.76 \mathrm{~m} / \mathrm{s}$. The counterpart surface of pure EP is very rough and covered with many debris and furrows (Fig. 9a). While the counterpart surfaces of $\mathrm{PI} / \mathrm{EP}$ and $\mathrm{CNFs} / \mathrm{PI} / \mathrm{EP}$ composites are relatively smooth and merely have some furrows and scratches (Fig. 9b, 9c).

According to the tribological results and surface analysis, friction and wear mechanisms of PI/EP and CNFs/PI/EP composites are exhibited in Fig. 10. Compared to pure EP, PI fiber felt provide 3D structural support improving the load-capacity of composites. The debris of fibers are transferred from composites to the counterpart surfaces and filled in the micro-pit on the counterpart surface, restoring the defects of the surfaces and gradually forming transfer film during sliding. 
Steady transfer film can resist the contact between the worn and the counterpart surfaces [31]. As shown in Fig. 10b, CNFs/PI/EP nanocomposites provide both robust 3D interpenetrating structure and thermal conductive network, which achieve the best tribological properties. Moreover, plenty of PI fibers and CNFs are exposed on the worn surfaces and support the loads during the sliding. In particular, the transfer film of CNFs/PI/EP nanocomposites is formed by the deposition of the CNFs debris has the lubrication effect, makes an important contribution to the improvement in tribological properties of composites. Hence, slight adhesive wear is the main wear mechanism of CNFs/PI/EP composites.
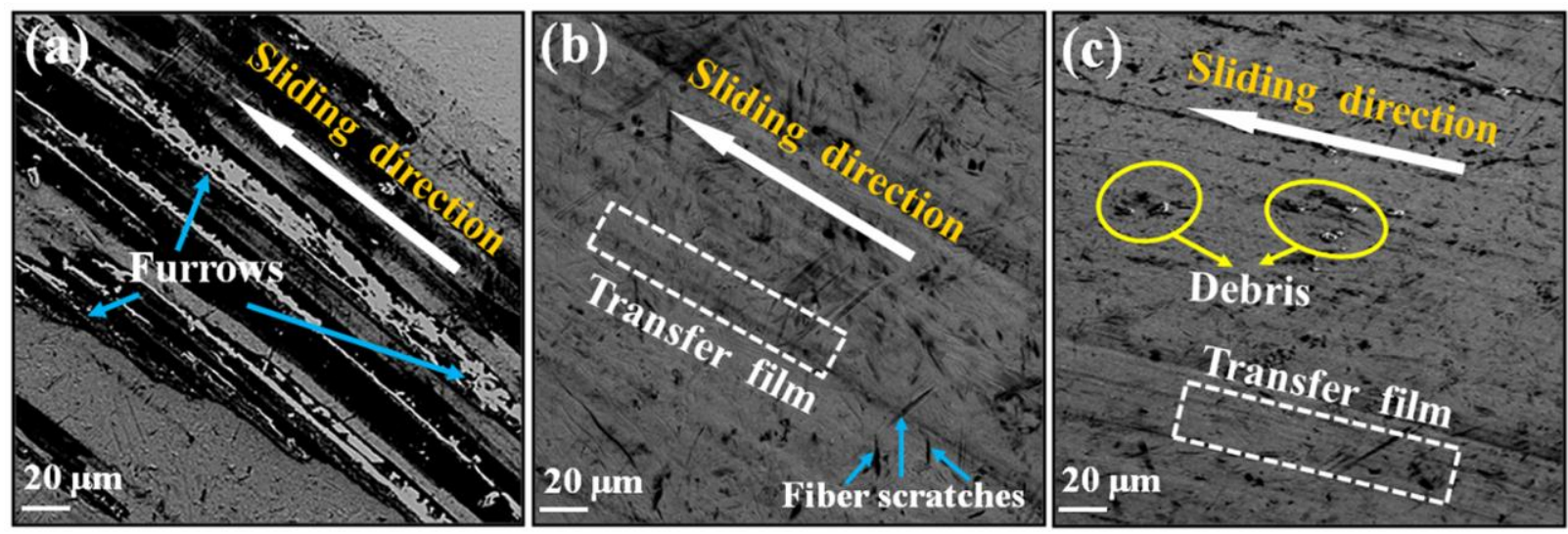

Fig.9. SEM morphology of the counterpart surfaces of (a) pure EP, (b) PI/EP composites, (c) 1.0

wt.\% CNFs/PI/EP nanocomposites under $1.2 \mathrm{MPa}$ and $0.76 \mathrm{~m} / \mathrm{s}$ conditions.

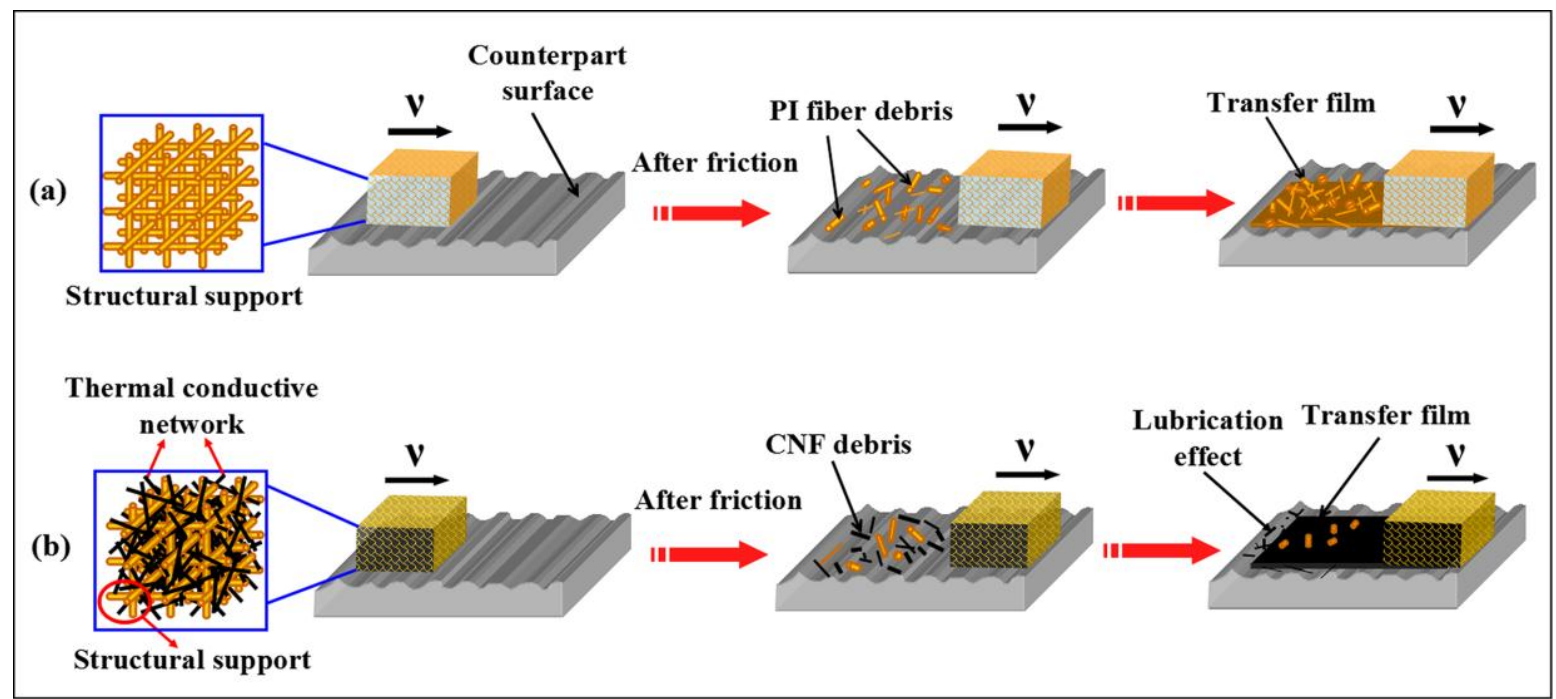

Fig.10. Friction and wear mechanism of (a) PI/EP and (b) CNFs/PI/EP composites. 


\section{Conclusions}

In this research, a new robust CNFs/PI/EP nanocomposite with 3D network has been prepared by VARTM process. The mechanical and tribological properties of nanocomposites are studied. The following conclusions can be drawn:

1. The 3D network provided by PI fiber felt can efficiently improve the structural strength of EP, realizing the significant increase of mechanical properties and wear resistance. The further incorporation of CNFs can greatly enhance the interface bonding strength between EP matrix and PI fiber felt, leading to the improvements of mechanical properties, lubricating effect and wear-resistance of CNFs/PI/EP composites.

2. $1.0 \mathrm{wt} \% \mathrm{CNFs} / \mathrm{PI} / \mathrm{EP}$ nanocomposites achieve the lowest friction coefficient and wear rate under varied loads and velocities. The wear resistance of CNFs/PI/EP nanocomposites is 18 times and 2 times higher than that of pure EP and PI/EP composites under $1.2 \mathrm{MPa}, 0.76 \mathrm{~m} / \mathrm{s}$, respectively.

3. The dominant wear mechanisms for pure EP are severe ploughing and adhesive wear. The synergistic effect of 3D PI fiber felt and CNFs significantly enhances the tribological performance of CNFs/PI/EP composites. The dominant wear mechanisms for PI/EP composites are minor ploughing wear and adhesive wear, while the mechanism for CNFs/PI/EP nanocomposites is slight adhesive wear.

\section{Acknowledgments}

The research is financially supported by the National Young Top Talents Plan of China (2013042), National Science Foundation of China (Grant No. 51175066), FANEDD (201164), New Century Excellent Talents in University (NCET-12-0704), the Science Foundation for Distinguished 
Young Scholars of Heilongjiang Province (JC201403) and Natural Science Foundation of Heilongjiang Province (E2015034).

\section{References}

[1] A.P. Mouritz, M.K. Bannister, P.J. Falzon, K.H. Leong, Review of applications for advanced three-dimensional fibre textile composites, Compos. Part A-Appl. S 30 (1999) 1445-1461.

[2] R.F. Gibson, A review of recent research on mechanics of multifunctional composite materials and structures, Compos. Struct. 92 (2010) 2793-2810.

[3] H.-T. Liu, Q.-S. Ma, W.-D. Liu, Mechanical and oxidation resistance properties of 3D carbon fiber-mullite matrix composites prepared by sol-gel process, Ceram. Int. 40 (2014) 7203-7212.

[4] M. Nanu, J. Schoonman, A. Goossens, Nanocomposite three-dimensional solar cells obtained by chemical spray deposition, Nano. lett. 5 (2005) 1716-1719.

[5] A. Vinu, S. Anandan, C. Anand, P. Srinivasu, K. Ariga, T. Mori, Fabrication of partially graphitic three-dimensional nitrogen-doped mesoporous carbon using polyaniline nanocomposite through nanotemplating method, Micropor. Mesopor. Mat. 109 (2008) 398-404.

[6] L.L. Lebel, B. Aissa, O.A. Paez, M.A. El Khakani, D. Therriault, Three-dimensional micro structured nanocomposite beams by microfluidic infiltration, J. Micromech. Microeng. 19 (2009) 125009.

[7] A. Montazeri, J. Javadpour, A. Khavandi, A. Tcharkhtchi, A. Mohajeri, Mechanical properties of multi-walled carbon nanotube/epoxy composites, Mater. Design. 31 (2010) 4202-4208.

[8] M. Behzadnasab, S.M. Mirabedini, K. Kabiri, S. Jamali, Corrosion performance of epoxy coatings containing silane treated $\mathrm{ZrO}_{2}$ nanoparticles on mild steel in $3.5 \% \mathrm{NaCl}$ solution, Corros. Sci. 53 (2011) 89-98. 
[9] O. Becker, R. Varley, G. Simon, Morphology, thermal relaxations and mechanical properties of layered silicate nanocomposites based upon high-functionality epoxy resins, Polymer 43 (2002) 4365-4373.

[10] N. Chikhi, S. Fellahi, M. Bakar, Modification of epoxy resin using reactive liquid (ATBN) rubber, Eur. Polym. J. 38 (2002) 251-264.

[11] X.-M. Tian, H.-B. Qiao, X.-F. Chu, Wear performance of bonded composite coatings under dry sliding, Surf. Coat. Tech. 240 (2014) 191-196.

[12] A. Allaoui, S. Bai, H.-M. Cheng, J.B. Bai, Mechanical and electrical properties of a MWNT/epoxy composite, Compos. Sci. Technol. 62 (2002) 1993-1998.

[13] Z.-H. Fan, M.H. Santare, S.G. Advani, Interlaminar shear strength of glass fiber reinforced epoxy composites enhanced with multi-walled carbon nanotubes, Compos. Part A-Appl. S 39 (2008) $540-554$.

[14] S.-L. Gao, E. Mäder, R. Plonka, Nanocomposite coatings for healing surface defects of glass fibers and improving interfacial adhesion, Compos. Sci. Technol. 68 (2008) 2892-2901.

[15] J.-L. Hu, Y. Zhu, H.-H. Huang, J. Lu, Recent advances in shape-memory polymers: Structure, mechanism, functionality, modeling and applications, Prog. Polym. Sci. 37 (2012) 1720-1763.

[16] D.-J. Liaw, K.-L. Wang, Y.-C. Huang, K.-R. Lee, J.-Y. Lai, C.-S. Ha, Advanced polyimide materials: syntheses, physical properties and applications, Prog. Polym. Sci. 37 (2012) 907-974.

[17] X.-R. Zhang, X.-Q. Pei, Q.-H. Wang, Friction and wear studies of polyimide composites filled with short carbon fibers and graphite and micro $\mathrm{SiO}_{2}$, Mater. Design. 30 (2009) 4414-4420.

[18] A.C. Balazs, T. Emrick, T.P. Russell, Nanoparticle polymer composites: where two small worlds meet, Science 314 (2006) 1107-1110. 
[19] S.-Y. Fu, X.-Q. Feng, B. Lauke, Y.-W. Mai, Effects of particle size, particle/matrix interface adhesion and particle loading on mechanical properties of particulate-polymer composites, Compos. Part B: Eng. 39 (2008) 933-961.

[20] S. Agarwal, M.M.K. Khan, R.K. Gupta, Thermal conductivity of polymer nanocomposites made with carbon nanofibers, Polym. Eng. Sci. 48 (2008) 2474-2481.

[21] L. Guadagno, M. Raimondo, V. Vittoria, L. Vertuccio, K. Lafdi, B. De Vivo, P. Lamberti, G. Spinelli, V. Tucci, The role of carbon nanofiber defects on the electrical and mechanical properties of CNF-based resins, Nanotechnology 24 (2013) 305704.

[22] I. Kang, Y.Y. Heung, J.H. Kim, J.W. Lee, R. Gollapudi, S. Subramaniam, S. Narasimhadevara, D. Hurd, G.R. Kirikera, V. Shanov, M.J. Schulz, D. Shi, J. Boerio, S. Mall, M. Ruggles-Wren, Introduction to carbon nanotube and nanofiber smart materials, Compos. Part B: Eng. 37 (2006) 382-394.

[23] Y.-Z. Wan, H.-L. Luo, Y.-L. Wang, Y. Huang, Q.-Y. Li, F.-G. Zhou, G.-C. Chen, Friction and wear behavior of three-dimensional braided carbon fiber/epoxy composites under lubricated sliding conditions, J. Mater. Sci. 40 (2005) 4475-4481.

[24] J.-H. Zhu, S.-Y. Wei, J. Ryu, M. Budhathoki, G. Liang, Z.-H. Guo, In situ stabilized carbon nanofiber (CNF) reinforced epoxy nanocomposites, J. Mater. Chem. 20 (2010) 4937-4948.

[25] S. Tian, X.-D. Wang, Fabrication and performances of epoxy/multi-walled carbon nanotubes/piezoelectric ceramic composites as rigid piezo-damping materials, J. Mater. Sci. 43 (2008) 4979-4987.

[26] Y.-J. Shi, X. Feng, H.-Y. Wang, X.-H. Lu, The effect of surface modification on the friction and wear behavior of carbon nanofiber-filled PTFE composites, Wear 264 (2008) 934-939. 
[27] I.G. Goryacheva, R.M. Martynyak, Contact problems for textured surfaces involving frictional effects, P. I. Mech. Eng J-J Eng. 228 (2014) 707-716.

[28] R. Spinola Barbosa, A 3D contact force safety criterion for flange climb derailment of a railway wheel, Vehicle. Syst. Dyn. 42 (2004) 289-300.

[29] A. Moisala, Q. Li, I.A. Kinloch, A.H. Windle, Thermal and electrical conductivity of single-and multi-walled carbon nanotube-epoxy composites, Compos. Sci. Technol. 66 (2006) 1285-1288.

[30] J.-S. Li, R.-Y. Luo, Y. Yan, Effect of carbon nanofibers on the infiltration and thermal conductivity of carbon/carbon composites, Mater. Res. Bull. 46 (2011) 1437-1442.

[31] S. Bahadur, The development of transfer layers and their role in polymer tribology, Wear 245 (2000) 92-99. 